Original Research Article

\title{
Efficacy of pregabalin versus nortriptyline in the treatment of chronic low backache with radiculopathy: an open label observational study
}

\author{
Annapurna V. T. ${ }^{1 *}$, Nivedita Maity ${ }^{1}$, Ravikumar T. V. ${ }^{2}$
}

\begin{abstract}
${ }^{1}$ Department of Pharmacology, ${ }^{2}$ Department of Orthopedics, M.S. Ramaiah Medical College and Hospitals. Bengaluru, Karnataka, India

Received: 17 May 2019

Revised: 06 June 2019

Accepted: 02 July 2019

*Correspondence to:

Dr. Annapurna V. T.,

Email: anuravi17@gmail.com

Copyright: (C) the author(s), publisher and licensee Medip Academy. This is an openaccess article distributed under the terms of the Creative Commons Attribution NonCommercial License, which permits unrestricted noncommercial use, distribution, and reproduction in any medium, provided the original work is properly cited.
\end{abstract}

\begin{abstract}
Background: The efficacy and safety of Pregabalin and Nortriptyline have been proved individually in low backache with radicular pain. However, there are limited number of studies comparing the efficacy of Pregabalin and Nortriptyline in Chronic Low Backache (CLBA) with radicular pain. Hence the present study was designed to determine the efficacy as well as tolerability of Pregabalin in comparison with that of Nortriptyline for reduction of pain in CLBA. The present study was an open label prospective observational study.

Methods: Patients with CLBA, 15-60 years of age without specific cause and significant neurological deficit were included in the study. Severity of pain was assessed by Visual Analogue Scale (VAS). Patients were followed up at 2 and 4 weeks and their VAS scores and side effects were noted.

Results: Both Pregabalin and Nortriptyline were effective in reducing pain, from baseline to 2 weeks and up to 4 weeks of treatment in chronic low backache with radicular pain, but there was no statistically significant difference between the two treatment groups. The incidences of side effects were less in the Nortriptyline treatment group as compared to Pregabalin.

Conclusions: From the results of the present study it can be concluded that both Pregabalin and Nortriptyline were equally effective in the treatment of chronic low backache with radicular pain, but the incidence of adverse effects were more with Pregabalin as compared to Nortriptyline.
\end{abstract}

Keywords: Chronic low backache, Efficacy, Nortriptyline, Pregabalin, Tolerability

\section{INTRODUCTION}

Low back pain (LBP) is the most common clinical, social and public health problem affecting people worldwide. The incidence of chronic low back pain ranges from $15 \%$ to $45 \%$ with a prevalence of $30 \%$ in industrialized countries. ${ }^{1}$ LBP is defined as pain localised to the lumbosacral region of the spine, referred to the leg or foot. The most frequent location being the $4^{\text {th }}$ and $5^{\text {th }}$ lumbar segment. Usually the acute pain lasts for <4weeks, subacute 4-12weeks and chronic >12 weeks. ${ }^{2}$ Radicular pain is typically sharp and radiates from the low back to a leg within the territory of a nerve root. The pain may increase in postures that stretch the nerves and nerve roots. Sitting with the leg outstretched causes traction on the sciatic nerve, L5 and S1 roots as the nerve passes posterior to the hip. ${ }^{3}$

The first line of drugs for LBP is Non-Steroidal Antiinflammatory agents (NSAIDs). NSAIDS are frequently associated with GI and renal side effects. Drugs like Opioids produce analgesia but they can cause respiratory depression along with sedation. Skeletal muscle relaxants produce short term pain relief with sedation as CNS side effect. However, the anticonvulsants and antidepressants have been shown to produce better pain relief in LBP with radicular pain. ${ }^{4}$ 
Pregabalin, an anticonvulsant, is a (Gamma Amino Butyric Acid) GABA analogue exerts a specific analgesic effect in neuropathic pain. Recently it was found that it modulates voltage sensitive calcium channel which contain $\alpha 2 \delta$-1 subunits thereby decreasing the influx of calcium by inhibiting the release of excitatory neurotransmitters in neurons at the synaptic ending thereby reducing pain. ${ }^{5}$

Nortriptyline, is a tricyclic antidepressant a drug with reduced antimuscarinic effects acts by enhancing the activity in noradrenergic pain inhibitory pathway in the spinal cord thereby decreasing radicular pain. ${ }^{6}$

The efficacy and safety of Pregabalin and Nortriptyline have been proved individually in LBP with radicular pain. However, there is a limited number of studies comparing the efficacy of Pregabalin and Nortriptyline in this condition. Hence the present study is planned to determine the efficacy as well as tolerability of Pregabalin in comparison with that of Nortriptyline.

\section{METHODS}

This was a prospective, open-label, hospital-based study Patients who are clinically diagnosed as a chronic low back ache with radicular pain $(\mathrm{N}=114)$ and fulfilling the inclusion criteria and willing for follow up were recruited to the study. the data collected from the Orthopaedic outpatient department at M.S. Ramaiah Hospital, Bangalore, Karnataka, India. Institutional ethics committee approval was obtained. Study period was from November 2014 to December 2015 The study participants were recruited based on following inclusion and exclusion criteria; written informed consent was obtained from all the patients. 57 patients to receive Pregabalin $75 \mathrm{mg}$ orally once daily and the other arm 57 patients to receive Nortriptyline $25 \mathrm{mg}$ once daily both after food at the bedtime.

In the first visit to the hospital a baseline demographic data (age, gender, diseases, habits, drug history and surgical history) were collected. Initial history for evaluation of low back pain such as duration, location, radiation and intensity of pain were also recorded. The severity of pain was measured by Visual Analogue Scale (VAS). The pain intensity and adverse events were recorded using VAS after 2 weeks of the treatment and followed up for another
2 weeks. At the end of the 4 weeks of treatment, the changes in efficacy parameter VAS and adverse events were noted and compared between the two arms.

\section{Inclusion criteria}

- Patients aged between 18-60 years having chronic LBP with radicular symptoms

- Lumbar radicular symptoms present for more than 3 months.

- Symptoms involving one or both lower limbs or buttocks.

- Leg pain of 6-7/10 at least 1 month on a Visual Analogue Scale.

\section{Exclusion criteria}

- Medical comorbidities such as unstable angina disease, advanced diabetes, hypertension and cancer.

- Pregnancy or lactation.

- History of depression requiring treatment with antidepressants within 6 months preceding study participation.

- Patients with Cervical or Thoracic myelopathy.

- Fibromyalgia.

- Pain of greater intensity of any other spinal location other than Low back and lower limbs.

Tolerability was assessed based on patient reporting of adverse events.

\section{Statistical analysis}

Sample size was calculated based on a literature review from the study by J.Kalita et al, using an improvement in pain as outcome criteria $(57.3 \%$ Vs $39.2 \%)$ after intervention by comparing two independent samples. Chi square test was used to compare the VAS score improvement between two drugs.

\section{RESULTS}

A total of 114 patients were analysed both male and female patients were included in this study. In the present study, the baseline demographic data like age, sex, BMI visual analogue score were almost similar in both the study group (Table 1).All the quantitative variables like age were expressed as mean and standard deviation.

Table 1: Baseline characteristics of the study subjects.

\begin{tabular}{|llll|}
\hline & Pregabalin $(\mathbf{n = 5 7})$ & Nortriptyline $(\mathbf{n}=\mathbf{5 7})$ & P value \\
\hline Age & $42.9+10.762$ & $44.75+11.350$ & 0.345 \\
\hline Male & 31 & 26 & 0.353 \\
\hline Female & 26 & 31 & 0.013 \\
\hline Body mass index $(\mathrm{BMI})\left(\mathrm{kg} / \mathrm{m}^{2}\right)$ & $23.95 \pm 3.324$ & $22.54 \pm 2.571$ & 0.532 \\
\hline Baseline VAS score & $6.19+0.581$ & $6.26+0.613$ & \\
\hline
\end{tabular}


All the qualitative variables were expressed as proportion. Age is comparable between two groups with the $\mathrm{p}$ value $=0.285 .38 .6 \%$ of patients belonged to the age group of 31 40 years in the pregabalin group whereas $36.84 \%$ of patients belonged to the age group of 51-60 years in the nortriptyline group (Table 2). In the current study more than $50 \%$ of the patients belonged to more than 40 years of age.

Table 2: Age distribution of the study subjects.

\begin{tabular}{|c|c|c|c|c|}
\hline \multirow{3}{*}{$\begin{array}{l}\text { Age } \\
\text { (years) }\end{array}$} & \multicolumn{4}{|c|}{ Treatment groups } \\
\hline & \multicolumn{2}{|c|}{ Pregabalin } & \multicolumn{2}{|c|}{ Nortriptyline } \\
\hline & $(n=57)$ & $\%$ & $(n=57)$ & $\%$ \\
\hline $18-20$ & 1 & 1.75 & 1 & 1.75 \\
\hline $21-30$ & 5 & 8.77 & 8 & 14.04 \\
\hline $31-40$ & 22 & 38.6 & 13 & 22.81 \\
\hline $41-50$ & 16 & 28.07 & 14 & 24.56 \\
\hline $51-60$ & 13 & 22.81 & 21 & 36.84 \\
\hline Total & 57 & 100 & 57 & 100 \\
\hline
\end{tabular}

\begin{tabular}{|c|c|}
\hline males & females \\
\hline 45.61, & 54.38 \\
$46 \%$ & $54 \%$ \\
& \\
& \\
& \\
\hline & \\
\hline
\end{tabular}

Figure 1(A): Gender distribution of the study subjects

In the pregabalin group majority of the study subjects were males $(54.38 \%)$ as compared to that of nortriptyline group where it was $45.61 \%$ (Figure 1). The baseline BMI in the pregabalin and nortriptyline groups were $23.95+3.32$ $\mathrm{kg} / \mathrm{m}^{2}$ and $22.54+2.57 \mathrm{~kg} / \mathrm{m}^{2}$ respectively indicating that there is a statistically significant difference in BMI values between the two groups ( $p$ value $=0.013$ ) (Table 1$)$. Both the study groups showed similar percentage of patients having normal BMI however, the pregabalin group had more overweight patients (Figure 2). This observation indicates that chronic low backache with radicular pain is more common among adults and the elderly age groups.

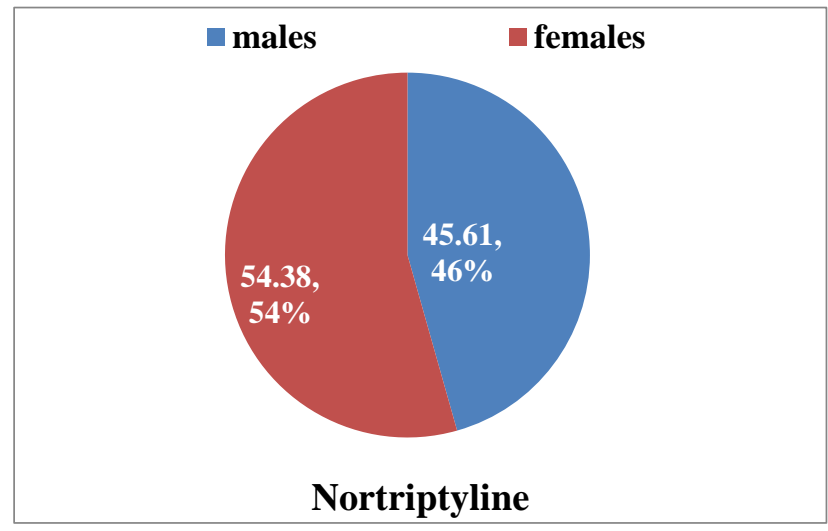

Figure 1(B): Gender distribution of the study subjects.

Table 3: Mean distribution of pain score in the study subjects using VAS.

\begin{tabular}{|c|c|c|c|}
\hline \multirow{2}{*}{$\begin{array}{l}\text { Visual } \\
\text { analogue } \\
\text { scale }\end{array}$} & \multicolumn{2}{|c|}{ Treatment groups } & \multirow{2}{*}{$\begin{array}{l}\mathbf{p} \\
\text { value }\end{array}$} \\
\hline & Pregabalin & Nortriptyline & \\
\hline $\begin{array}{l}\text { VAS at } \\
\text { baseline }\end{array}$ & $6.19+0.581$ & $6.26+0.613$ & 0.532 \\
\hline $\begin{array}{l}\text { VAS after } \\
\text { 2weeks }\end{array}$ & $3.79+0.803$ & $3.67+0.747$ & 0.444 \\
\hline $\begin{array}{l}\text { VAS after } \\
\text { 4weeks }\end{array}$ & $2.64+1.043$ & $2.65+0.673$ & 0.914 \\
\hline
\end{tabular}

In the present study it was observed that between baseline, week 2 and week 4 there was a significant difference in the VAS score in both the treatment groups with a $\mathrm{p}<0.001$ (Table 3). However, in the pregabalin group, with a dose of $75 \mathrm{mg}$ /day the pain score had decreased from a mean of $6.19+0.58$ to $3.79+0.803$ after 2 weeks of treatment and from a mean of $6.19+0.58$ to $2.64+1.043$ after 4 weeks of treatment.

The side effects observed in the two study groups were sedation, vertigo, dry mouth, restlessness, postural hypotension and urinary retention (Table 4).

Table 4: Side effect profile of the study groups.

\begin{tabular}{|lllll|}
\hline \multirow{2}{*}{ Side effects } & \multicolumn{2}{l|}{ Treatment groups } \\
& Pregabalin & & Nortriptyline \\
\cline { 2 - 5 } & After 2 weeks & After 4 weeks & After 2 weeks & After 4 weeks \\
\hline Sedation & 21 & 21 & 2 & 2 \\
\hline Vertigo & 17 & 4 & 4 & 4 \\
\hline Dry mouth & 6 & 6 & 21 & 18 \\
\hline Restlessness & 12 & 12 & 1 & 1 \\
\hline Postural hypotension & 0 & 0 & 18 & 6 \\
\hline Urinary retention & 0 & 0 & 9 & 6 \\
\hline
\end{tabular}


The incidence of sedation, vertigo and restlessness were more in the pregabalin study group of which vertigo was reduced after 4 weeks of treatment whereas dry mouth, sedation and restlessness remained the same throughout the course of treatment. The incidence of dry mouth, postural hypotension and urinary retention were more in the nortriptyline treatment group with a slight reduction in the incidence of dry mouth, postural hypotension and urinary retention after 4 weeks of treatment.

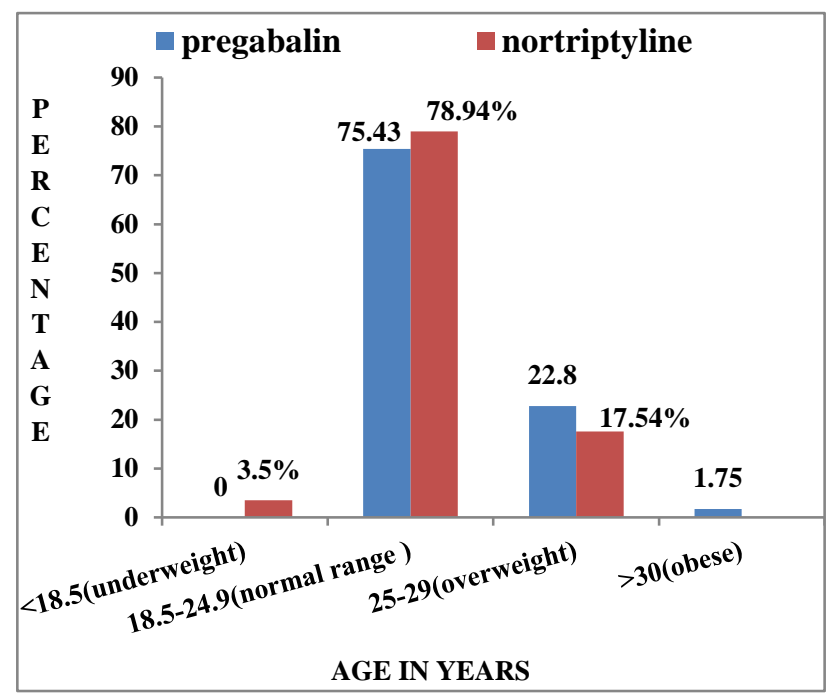

Figure 2: Graphical representation of BMI of the study subjects.

\section{DISCUSSION}

The present study was carried out for a period of 1 month for each patient with a follow up at $2^{\text {nd }}$ and $4^{\text {th }}$ week to compare the efficacy and tolerability of pregabalin and nortriptyline in chronic low backache with radicular pain. In the present study, the baseline demographic data like age, sex, BMI and VAS score were almost similar in both the study groups. In the current study more than $50 \%$ of the patients belonged to more than 40 years of age and this is similar to an observation in a previous study done in India by Kalita et al, whereas $40.8 \%$ of the participants belonged to the same age range.

This observation indicates that chronic low backache with radicular pain is more common among adults and the elderly age groups. Both the study groups showed similar percentage of patients having normal BMI however, the pregabalin group had more overweight patients (Figure 2). It was also observed in the present study that $43.8 \%$ of patients in pregabalin group reported reduction from severe to mild pain at the end of 2 weeks, $84.2 \%$ at the end of 4 weeks and $7.01 \%$ of patients showed no pain at the end of 4 weeks . This observation is slightly different from a trial done by Baron $\mathrm{R}$ et al, which reported that, at the end of the single blind pregabalin treatment phase with a flexible-dose of $150-600 \mathrm{mg} /$ day, the pain score had decreased from mean baseline pain of 6.4 to a mean of 2.3.
$57.9 \%$ patients experienced $>30 \%$ reduction in pain and $34 \%$ of patients reported $>50 \%$ of less pain. ${ }^{7}$

A study done by Orbai et al, where 20 out of 26 patients with chronic low backache improved following amitriptyline or nortriptyline treatment and majority (55\%) of them showed improvement at a dose of $10 \mathrm{mg} / \mathrm{day} .{ }^{8}$

The analgesic effect of tricyclic antidepressants (TCAs) has also been reported in chronic low backache without depression. In a placebo controlled trial on 78 patients with chronic low backache without depression, nortriptyline resulted in reduction in pain severity by $22 \%$ compared to $9 \%$ by placebo. Disability, health related quality of life, mood and physician rating of overall outcome however were not changed significantly compared to placebo. ${ }^{9}$

The side effects observed in the two study groups were sedation, vertigo, dry mouth, restlessness, postural hypotension and urinary retention.

In a study by Max MB et al, the most common side effects of TCAs observed were sedation and anticholinergic effects (e.g., dry mouth, constipation, urinary retention and orthostatic hypotension). ${ }^{10}$ The incidence of anticholinergic side effects of TCAs observed in the present study is in accordance with the observations reported by Max MB et al.

\section{CONCLUSION}

Low backache is a common problem with a prevalence of $30 \%$ in industrialized countries. As there was no statistically significant difference in the results of the evaluation of pain scores of the two treatment groups, it can be concluded that both drugs were equally effective in treating chronic low backache with radicular pain.

However, nortriptyline seemed to be slightly better in reducing severity of pain as well as disability compared to pregabalin. With respect to the safety profile, more adverse effects were seen in the pregabalin treatment group as compared to the nortriptyline treatment group. Hence, it could be inferred that nortriptyline is slightly superior than pregabalin in terms of efficacy \& tolerability in the treatment of CLBA with radicular pain.

Further studies need to be done on a large scale and long term basis to compare the efficacy and tolerability of pregabalin versus nortriptyline in chronic low backache with radicular pain. Also, there is a need to have a dose comparison study (low versus high dose) in the Indian population to understand the differential response in the treatment of CLBA with radicular pain.

\section{ACKNOWLEDGEMENTS}

Authors would like to thank MS Ramaiah Medical college, Karnataka, India for approving the study and Department 
of Pharmacology and Orthopaedics, for their eminent support during study.

Funding: No funding sources

Conflict of interest: None declared

Ethical approval: The study was approved by the Institutional Ethics Committee

\section{REFERENCES}

1. Sardar K, Das G, Mahta P, Mallick S, Hubbard R. Medical ozone in herniated disc: A classical review. J Pain Relief. 2014;3(3):1000148.

2. Nordin M, Balague F, Cedraschi C. Nonspecific low back pain surgical versus non-surgical treatment. Clinical orthopaedics and related research. Lippincott Williams and Willkins 2006;443:157-67.

3. Chou R, Qaseem A, Snow V, Casey D, Cross JT, Shekelle P, et al. Diagnosis and treatment of low back pain: a joint clinical practice guideline from the American College of Physicians and the American Pain Society. Ann Intern Med. 2007 Oct 2;147(7):47891.

4. Kalita J, Kohat AK, Misra UK, Bhoi SK. An open labeled randomized controlled trial of pregabalin versus amitriptyline in chronic low backache. J Neurol Scie. 2014 Jul 15;342(1-2):127-32.
5. KD Tripathi. Textbook of Pharmacology. $8^{\text {th }}$ ed. New Delhi: Jaypee brother's medical publishers; 2019:446.

6. Katzung and Trevor. Special Aspects of Geriatric Pharmacology. Basic and Clinical Pharmacology. $13^{\text {th }}$ ed. Mc Graw Hill; 2016:1054.

7. Freynhagen R, Baron R. The evaluation of neuropathic components in low back pain. Curr Pain Headache Rep. 2009;13(3):185-90.

8. Orbai AM, Meyerhoff JO. The effectiveness of tricyclic antidepressants on lumbar spinal stenosis. Bull NYU Hosp Jt Dis. 2010 Jan 1;68(1):22-4.

9. Atkinson JH, Slater MA, Williams RA, Zisook S, Patterson TL, Grant I et al. A placebo controlled randomized clinical trial of nortriptyline for chronic low back pain. Pain. 1998;76(3):287-96.

10. Max MB, Culnane M, Schafer SC, Gracely RH, Walther DJ, Smoller B, et al. Amitriptyline relieves diabetic neuropathy pain in patients with normal or depressed mood. Neurology. 1987;37(4):589-96.

Cite this article as: Annapurna VT, Nivedita M, Ravikumar TV. Efficacy of pregabalin versus nortriptyline in the treatment of chronic low backache with radiculopathy: an open label observational study. Int J Basic Clin Pharmacol 2019;8:1749-53. 